\title{
CURRENT REVIEW OF THE JUPITER, SATURN, AND URANUS IONOSPHERES
}

\author{
J. H. Waite, Jr* and T. E. Cravens** \\ ${ }^{*}$ NASA Marshall Space Flight Center, Huntsville, AL 35812, U.S.A. \\ ** Space Physics Research Laboratory, University of Michigan, Ann Arbor, MI \\ 48109, U.S.A.
}

ABSTRACT

\begin{abstract}
The ionospheres of the major planets Jupiter, Saturn, and Uranus are reviewed in light of Pioneer and Voyager observations. Some refinements to pre-Voyager theoretical models are required to explain the results, most notably the addition of significant particle ionization from "electroglow" and auroral processes and the need for additional chemical loss of protons $v$ la charge exchange reactions with water. Hater from the Saturn rings has been identified as a major modifier of the saturn ionosphere and water influx from satellites and/or meteorites may also be important at Jupiter and Uranus as well, as evidenced by the observed lonospheric structure and the identification of cold stratospheric carbon monoxide at Jupiter.
\end{abstract}

INTRODUCTION

Many excellent reviews have been written on the development of photochemical models for the study of the ionospheres of the major planets /1-5/. Therefore, no attempt will be made here to reproduce a historical summary of the development of the important photochemical schemes for modeling the outer planet ionospheres. Furthermore, there will be little discussion of the neutral atmospheres of these planets. The neutral atmosphere models will be taken from the Voyager UVS solar and stellar occultation analysis at Jupiter by Festou et al. $/ 6 /$, at Saturn by Festou and Atreya $/ 7 /$ and Smith et al. $/ 8 /$, and at Uranus by Broadfoot et al. $19 \%$ The purpose of this paper is to review the observational data from the $P$ ioneer and Voyager satellites of the outer planet ionospheres and discuss the required modifications to the pre-Voyager lonospheric models referenced above. We will begin with a brief overview of the pre-Voyager ionosphere chemistry, then discuss the Pioneer and Voyager measurements, followed by a post-Voyager analysis of the present state of knowledge of the Jupiter, Saturn, and Uranus ionospheres. Finally, a summary will be presented of outstanding problems to be solved in order to make further progress.

\section{Ion Chemistry Overview}

$\mathrm{H}_{2}$ is the major neutral gas in the Jupiter, Saturn, and Uranus atmospheres. Therefore, it follows that the major ion formed in the upper atmosphere due to photoionization or particle impact is $\mathrm{H}_{2}{ }^{+}$. Once formed, $\mathrm{H}_{2}^{+}$reacts quickly with $\mathrm{H}_{2}$ forming $\mathrm{H}_{3}^{+}$, breaking an $\mathrm{H}_{2}$ bond in the process. Earlier models used a rapld recombination rate for $\mathrm{H}_{3}^{+} / 10 /$ which resulted in a small contribution of $\mathrm{H}_{3}{ }^{+}$to the ionosphere. The major ionospheric ion was $\mathrm{H}^{+}$, formed chiefly as a result of dissociative ionization of $\mathrm{H}_{2}$ by photons or particles. The only loss of $\mathrm{H}^{+}$in the topside ionosphere was the slow process of radiative recombination which led to the dominance of $\mathrm{H}^{+}$in the ionosphere and to a long lifetime for the lonosphere itself (>10 s, several planetary rotations).

Recent results, however, suggest that the vibrational distribution of both $\mathrm{H}_{3}^{+}$and $\mathrm{H}_{2} \mathrm{may}^{+}$be extremely important in determining ionospheric structure. McElroy /2/ first guggested that $\mathrm{H}_{2}$ excited to $\mathrm{V}>4$ levels could possibly charge exchange with $\mathrm{H}^{+}$and provide an additional loss for protons in the ionosphere. Subsequent models by Atreya et al. $/ 11 /$, McConnell et al. $/ 12 /$, and waite et al. $/ 13 /$ used this reaction to help explain observed lonospheric profiles at Jupiter. However, these studies simply assumed a vibrational temperature profile for $\mathrm{H}_{2}$. More recent calculations of the vibrational distribution of $\mathrm{H}_{2}$ in the upper atmosphere /14/ do indeed suggest an elevated and highly non-Boltzmann distribution of $\mathrm{H}_{2}$ in the Jupiter upper atmosphere which can have substantial effects on the lonospheric profile.

Furthermore, very recent results by Smith and Adams /15/ and Michels and Hobbs /16/ 1ndicate that $\mathrm{H}_{3}{ }^{+}$recombines very slowly in its ground vibrational state and does not rapidiy recombine unless $\mathrm{V}>3$. Although the reaction of $\mathrm{H}_{2}^{+}$with $\mathrm{H}_{2}$ to form $\mathrm{H}_{3}^{+}$generally results in vibrationally excited $\mathrm{H}_{3}^{+} / 3 /$, competing processes such as vibration-translation (V-T) 
de-excitation by $\mathrm{H}_{2}$ collisions and spontaneous radiative transitions are efficient in reducing $\mathrm{H}_{3}{ }^{+}$to 1 ts ground state level. This increases the concentration of $\mathrm{H}_{3}{ }^{+}$in the ionosphere due to slowed recombination.

Topside ions such as $\mathrm{H}_{3}{ }^{+}, \mathrm{H}_{2}^{+}$, and $\mathrm{H}^{+}$can be rapidly lost by reaction with methane, $\mathrm{CH}_{4}$, forming the terminal ions $\mathrm{CH}_{5}^{+}$and $\mathrm{C}_{2} \mathrm{H}_{5}{ }^{+}$and higher order hydrocarbon ions. Therefore, the strength of eddy mixing in the atmosphere can also be important in determining ionospheric structure. Results by Waite et al. $/ 17 /$ showed that for a gold isothermal thermosphere, values of the eddy diffusion coefficient from $10^{4}$ to $10^{6} \mathrm{~cm}^{2} \mathrm{~s}^{-1}$ resulted in an ionosphere composed of $\mathrm{H}^{+}$with peak densities of $>10^{5} \mathrm{~cm}^{-3}$. Large values of the eddy diffusion coefficient $\left(10^{9} \mathrm{~cm}^{2} \mathrm{~s}^{-1}\right)$ resulted in large abundances of $\mathrm{CH}_{4}$ in the region of maximum ionization. The enhanced chemical 1088 of $\mathrm{H}^{+}$and $\mathrm{H}_{2}{ }^{+}$to methane leads to a decrease in the peak electron density to $10^{3} \mathrm{~cm}^{-3}$. High exospheric temperatures moderated this effect by moving the solar extreme ultraviolet ionization region away from the methane layer. Furthermore, there is increasing evidence /18,19/ that the influx of $\mathrm{H}_{2} \mathrm{O}$ in the outer planet lonospheres from rings, satellites, and meteorites may significantly affect lonospheric structure at Jupiter, Saturn, and Uranus. A schematic of the standard outer planet ionospheric chemistry is shown in Figure 1; additional $\mathrm{H}_{2} \mathrm{O}$ chemistry can be found in Figure 15.

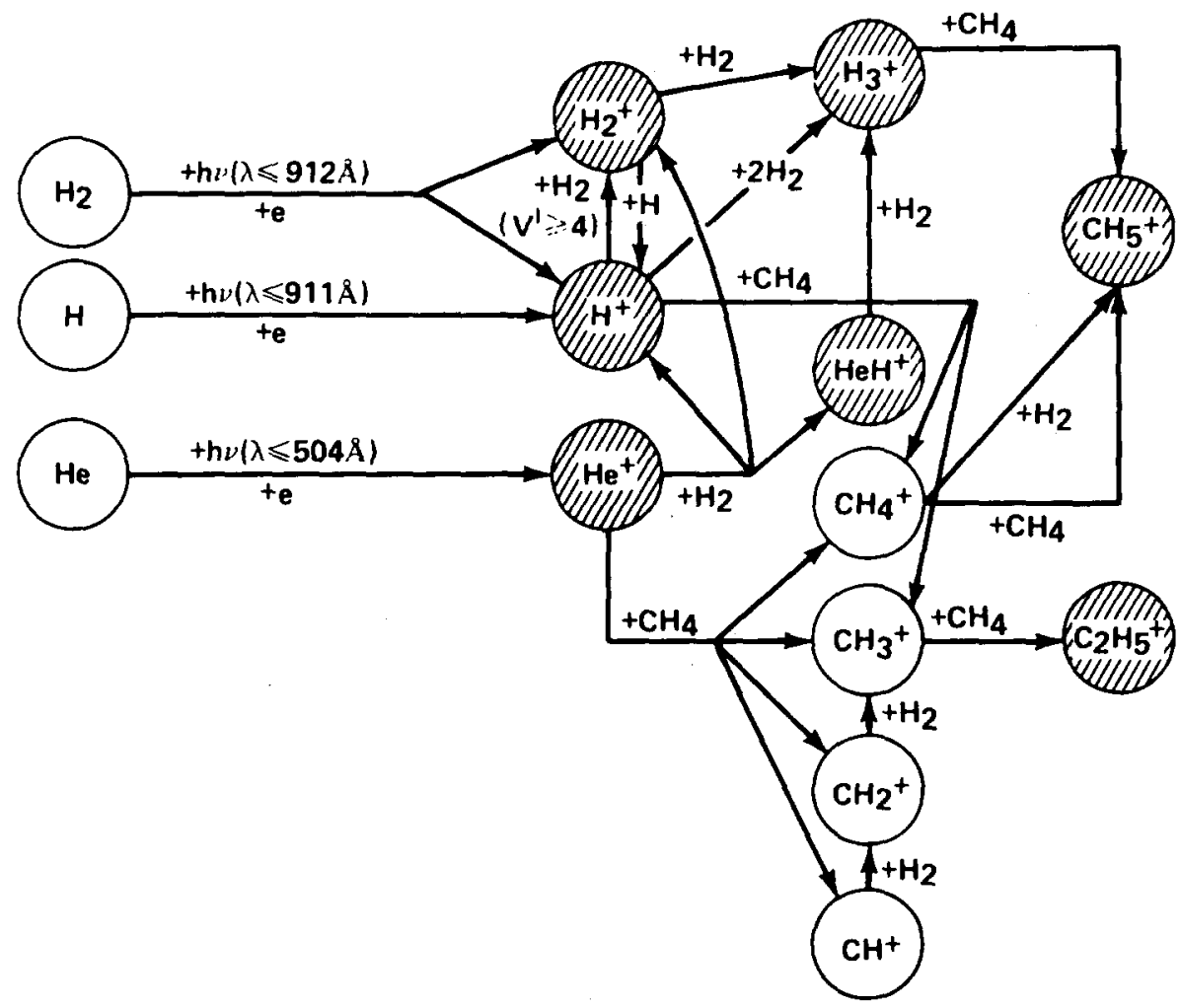

Fig. 1. Schematic depicting the important ion chemistry processes in the ionospheres of Jupiter and Saturn (from $/ 34 /$ ).

\section{Sources of Ionization}

Prior to the Voyager mission, solar extreme ultraviolet (EUV) radiation was considered to be the major source of ionization for the outer planet ionospheres. However, the Voyager Ultraviolet Spectrometer (UVS) observations indicated that particle precipitation may play an important role in determining the ionospheric structure even at low- or mid-latitudes. The Voyager UVS observed signiflcant Lyman and Werner band emissions from $\mathrm{H}_{2}$ over the whole dayside disk of Jupiter, Saturn, and Uranus. The phenomenon has been termed the "electroglow" by Broadfoot et al. $19 /$. Shemansky $/ 20 /$ suggests that soft electrons at high alt1tudes are responsible for the observed phenomenon at Jupiter. However, more recent sbservations of the $11 \mathrm{mb}$ of the atmosphere at Saturn /21/ and Uranus /19/ suggest that the source of the "electroglow" emissions is deep in the atmosphere just above the homopause. This may indicate separate "electroglow" mechanisms operative at the different planets and strongly suggests further analysis and observations are needed. The inferred column integrated energy deposition rates for the three planets are: Jupiter $0.32 \mathrm{erg} \mathrm{cm}^{-2} \mathrm{~s}^{-1}, \mathrm{Saturn} 0.13$ erg $\mathrm{cm}^{-2} \mathrm{~s}^{-1}$, and Uranus $0.10 \mathrm{erg} \mathrm{cm}^{-2} \mathrm{~s}^{-1}$. The UVs spectra also indicated that each planet 
has a characteristic electron energy that is associated with the electroglow process: Jupiter $50 \mathrm{ev}$, Saturn $30 \mathrm{eV}$, and Uranus $15 \mathrm{eV}$ electrons.

The particle "electroglow" Ionization sources are included in all the modeling profiles in this study by simply introducing a flux of the appropriate energy electrons, distributed in altitude corresponding to the photoelectron production profile, and with a column integrated energy flux as suggested by the Voyager UVS measurements.

A sample tonospheric proftle for Jupiter is shown in Flgure 2. Both $\mathrm{H}_{3}{ }^{+}$and $\mathrm{H}_{2}$ vibrational chemistry effects as well as particle Ionization from the "electroglow" process (described above) are included in the profile. The vibrational temperature profile is a scaled-down particle precipitation case taken from Cravens /14/ which reaches an exospheric value of $2200 \mathrm{~K}$. The topside ionosphere $1 \mathrm{~s}$ dominated by $\mathrm{H}^{+}$with layers of $\mathrm{H}_{3}^{+}$and hydrocarbon ions just below the ionospheric peak. The peak density of $6.6 \times 10^{5} \mathrm{~cm}^{-3}$ lies at an altitude near $625 \mathrm{~km}$ above the 1 bar pressure reference level. The ionosphere $1 \mathrm{~s}$ very extended due to the hot exospheric temperature. Using this model lonosphere as a point of departure, let us now take a look at the measurements and see how they agree.

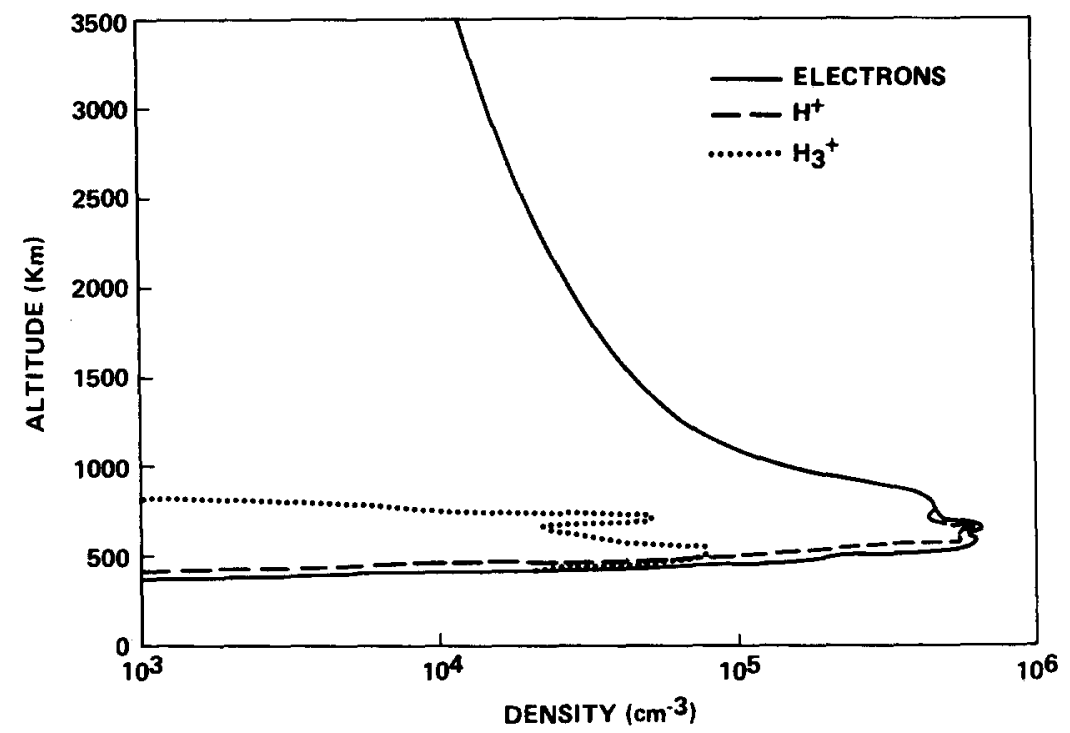

Fig. 2. Representative lonospheric profile for Jupiter using a high exospheric temperature of $100 \mathrm{~K}$ and a moderate eddy diffusion coefficient of $3 \times 10^{5} \mathrm{~cm}^{2} \mathrm{~s}^{-1}$. The model also includes the new $\mathrm{H}_{3}{ }^{+}$and $\mathrm{H}_{2}$ vibrational chemistry, and the "electroglow" particle ionization sources.

PIONEER AND VOYAGER IONOSPHERIC OBSERVATIONS

\section{Measurement Technique}

The structure of the ionospheres and tropospheres of the outer planets has been successfully measured by the technique of radio occultation employed on both the Pioneer and voyager spacecraft. Information on the gaseous envelope is obtained from measurements of Doppler frequency shift, group delay, intensity, and polarization of the radio signal when the spacecraft swings behind the planetary body and undergoes occultation as viewed from the Earth /22-24/. The Pioneer measurements were carried out using a single frequency (2.293 $\mathrm{GHz}$ or $\mathrm{s}-$ band at $13 \mathrm{~cm}$ ) radio link. The Voyager dual-frequency technique is particularly important for the outer planet lonospheres where multi-mode propagation of the beam is caused by sharp ionospheric layers /25/. Furthermore, the signal-to-noise ratio for Voyager exceeds the Pioneer s-band values by $10 \mathrm{~dB}$ at s-band frequencies and 23 dB at $x-b a n d ~ f r e-$ quencies $/ 25 /$. Due to geometric considerations, all ionospheric profiles are obtained near the dawn or dusk terminators.

\section{Jupiter Ionospheric Profiles}

The Pioneer 10 and 11 measurements of the Jovian ionosphere are shown in Figure 3 . The two most striking features in these profiles are: the large vertical extent of the 10 osphere indicative of the unexpected hot exospheric temperatures, and the mitilayered bottomside ionosphere. Multi-mode propagation effects make it hard to tell for certain which peaks are real $/ 26 /$. 


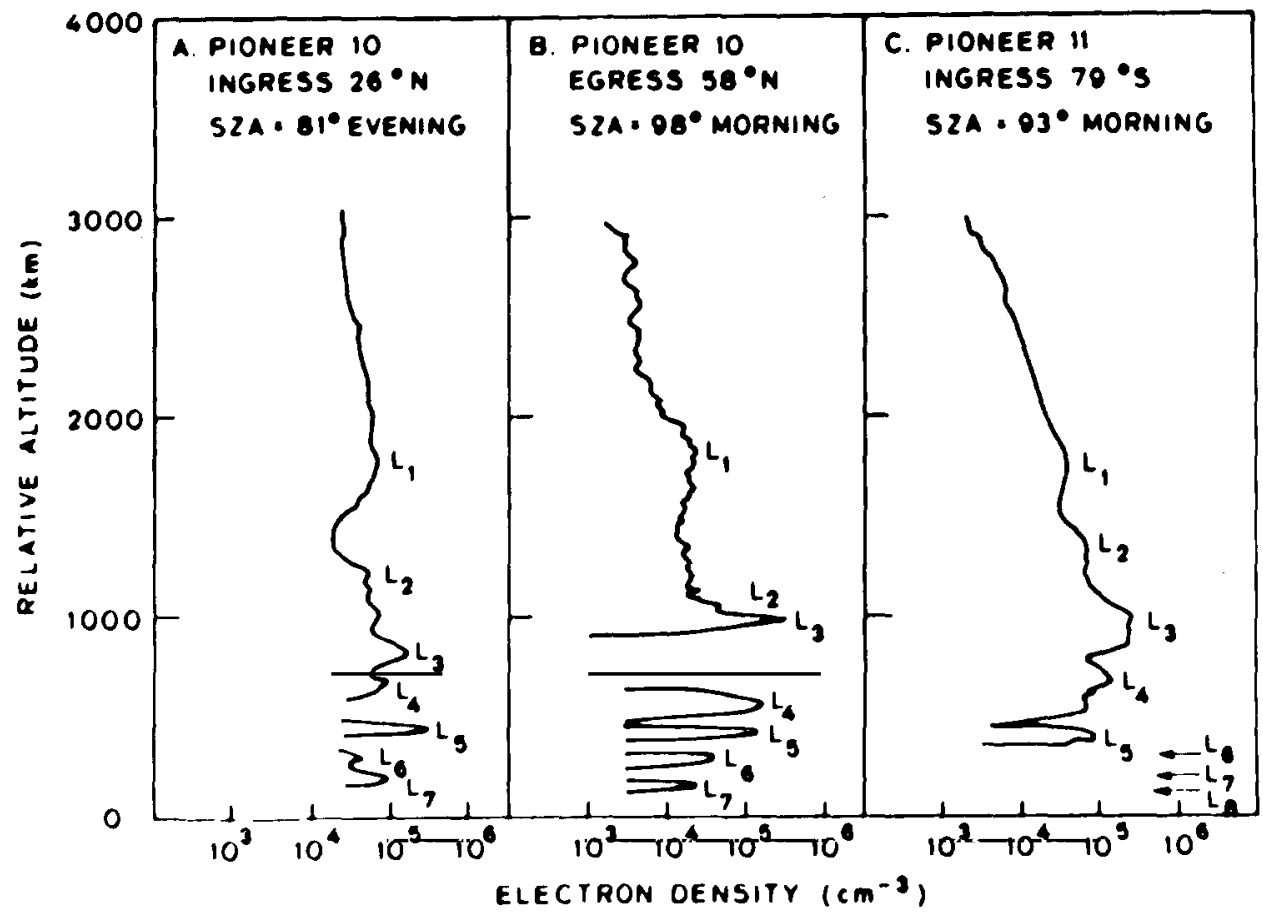

Fig. 3. Pioneer radio occultation profiles of Jupiter (from $/ 26 /$ ).

The Voyager 1 and 2 ionospheric measurements of Jupiter /27,28/ are shown in Figure 4. They verify the large vertical extent of the ionosphere but fail to give any information on the Ionospheric layers in the lower lonosphere, leaving this question open. The observations do, however, indicate two new pleces of information concerning ionospheric structure: (1) although both the $\mathrm{v}-1$ entry and exit occurred at low latitudes with the entry measurement being made at the dusk terminator and the exit measurement near the dawn terminator, there is a striking decreage in the peak ionospheric density; and (2) the lower altitude ionospheric profile seen at v-2 entry was taken very near the Jovian auroral zone and is most probably affected by auroral processes.

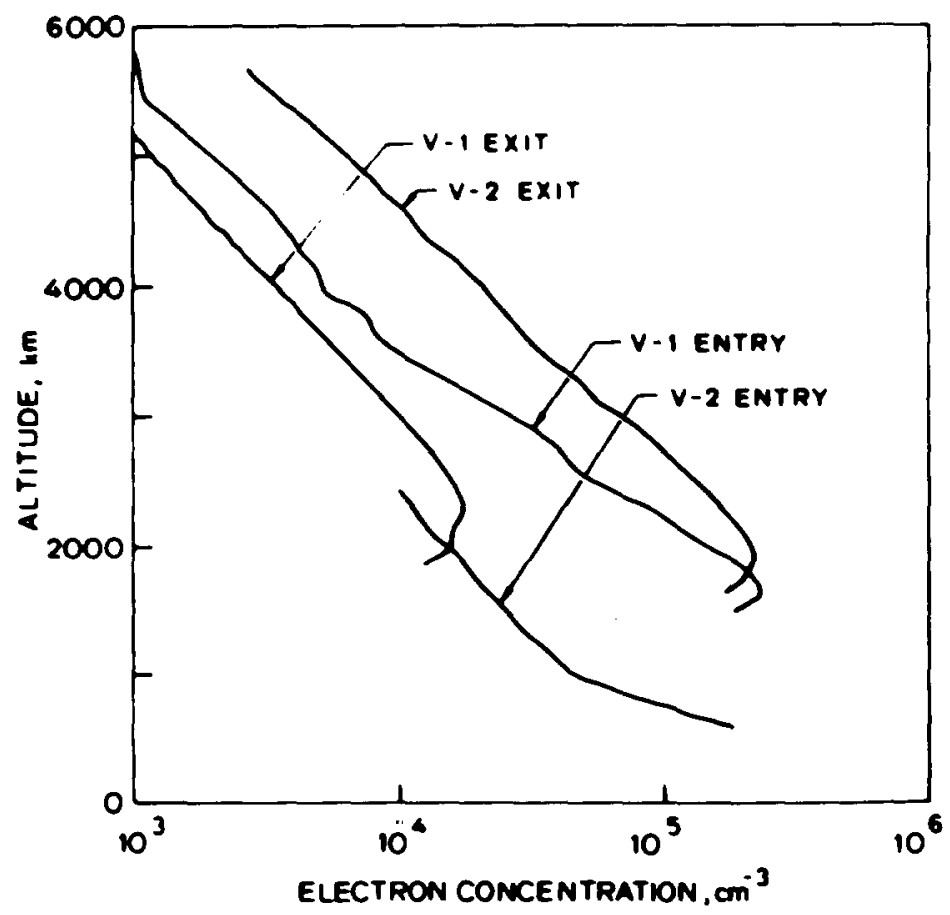

Fig. 4. Voyager radio occultation profiles of Jupiter (from $/ 27,28 /$ ). 


\section{Saturn Ionospheric Profiles}

The Ionosphere of Saturn was probed on six occasions between 1979 and 1981. With the exception of the Voyager 1 exit data which have not been fully analyzed, major characteristics of all other measurements are listed in Table 1. All measurements were made close to the terminator, 1.e., at solar zenith angle $90^{\circ}$.

TABLE 1 Location and Measured Characteristics of the Pioneer and Voyager Radio Occultation Measurements of the Saturn Ionosphere (from /34/).

\begin{tabular}{|c|c|c|c|c|c|c|}
\hline \multicolumn{7}{|c|}{ SATURN IONOSPHERE OBSERVATIONS } \\
\hline $\begin{array}{l}\text { OBSERVATION } \\
\text { DATE }\end{array}$ & TECHNIOUE & LATITUDE & $\begin{array}{l}\text { SOLAR } \\
\text { ZENITH } \\
\text { ANGLE }\end{array}$ & $\begin{array}{l}\text { PEAK ELECTRON } \\
\text { CONCENTRATION } \\
\left(\mathrm{am}^{-3}\right)\end{array}$ & $\begin{array}{l}\text { ALTITUDE" } \\
\text { OF THE } \\
\text { PEAK ABOVE } \\
\text { 1BAR LEVEL } \\
\text { (km) }\end{array}$ & $\begin{array}{l}\text { PLASMA } \\
\text { SCALE } \\
\text { HEIGHTS } \\
\{k \mathrm{k}\}\end{array}$ \\
\hline \multirow[t]{3}{*}{$\begin{array}{l}1979 \\
\text { SEPT. } 1\end{array}$} & PIONEER SATURN & & & & & \\
\hline & INGRESS & $11^{0} 65$ & $\begin{array}{l}89^{\circ} 2 \\
\text { TERMINATOR }\end{array}$ & $1.1 \times 10^{4}$ & 1900 & $?^{0}$ \\
\hline & EGRESS & $9^{\circ} 75$ & $\begin{array}{l}90^{\circ 9} \\
\text { TERMINATOR }\end{array}$ & $\sim 1 \times 10^{4}$ & 2900 & \\
\hline $\begin{array}{l}1980 \\
\text { NOV. } 12\end{array}$ & $\begin{array}{l}\text { VOYAGER } 1 \\
\text { S-AND X-BANDS } \\
\text { INGRESS }\end{array}$ & $73^{\circ} \mathrm{s}$ & $\begin{array}{l}89^{\circ} \\
\text { LATE AFTERNOON }\end{array}$ & $2.3 \times 10^{4}$ & 2500 & $560 \mathrm{~km}$ \\
\hline \multirow[t]{2}{*}{$\begin{array}{l}1981 \\
\text { AUG. } 26\end{array}$} & $\begin{array}{l}\text { VOYAGER } 2 \\
\text { S-AND X-BANDS } \\
\text { INGRESS }\end{array}$ & $36^{\circ} \mathrm{N}$ & $\begin{array}{l}87^{\circ} \\
\text { LATE AFTERNOON }\end{array}$ & $6.4 \times 10^{3}$ & 2850 & $\begin{array}{l}1000 \mathrm{~km} \text {, TOPSIDE } \\
260 \mathrm{~km} \text {, LOWER }\end{array}$ \\
\hline & EGRESS & $31^{\circ} \mathrm{S}$ & $\begin{array}{l}93^{\circ} \\
\text { PRE-DAWN }\end{array}$ & $1.7 \times 10^{4}$ & 2150 & $1100 \mathrm{~km}$, TOPSIDE \\
\hline
\end{tabular}

1-BAR LEVEL IS $\sim 75 \mathrm{~km}$ BELOW THE LEVEL AT WHICH THE ATMOSPHERIC DENSITY OF $10^{19} \mathrm{~cm}^{-3}$ IS AEACHED,

AND $50 \mathrm{~km}$ BELOW THE AMMONIA CLOUD TOPS.

ALTHOUGH THE PLASMA SCALE HEIGHT CANNOT BE DETERMINED WITH CERTAINTY ON THE PIONEER SATURN

RADIO OCCULTATION OATA. THE INGRESS DATA ARE MORE RELIABLE. THE DATA FOR N $\mathrm{N}_{c}<3 \times 10^{3} \mathrm{~cm}^{-3}$ IN THESE OBSERVATIONS MAY BE SPURIOUS.

The Pioneer radio occultation measurements revealed an ionosphere extending up to $30,000 \mathrm{~km}$ from the planetary $11 \mathrm{mb} / 29 /$. The entry (ingress) data are more reliable than the exit data. Data for concentrations $<3000$ electrons $\mathrm{cm}^{-3}$ may not be indicative of the local electron concentration on Saturn; they are more likely due to electron fluctuations of the interplanetary solar wind $/ 29 \%$. Figure 5 shows the entry and exit ionospheric data up to a radius of $70,000 \mathrm{~km}$. Despite differences in details, the two profiles show the same general characteristics. A peak electron concentration of $10^{4} \mathrm{~cm}^{-3}$ at $1800 \mathrm{~km}$ above the 1 bar pressure level (planetocentric distance 60,330 km) occurs in the entry profile, while a similar peak concentration is found nearly $1000 \mathrm{~km}$ higher in the exit data. The magnitude of the electron fluctuations of the interplanetary solar wind, associated with uncertainties In the orbit, and the oscillator drift render the exit data only marginally useful, and then only for qualitative comparison with the entry data $/ 29 /$. However, the altitude structure present in the data is not subject to these uncertainties and is accurate to the limitations set by spacecraft position information (plus or minus a few kilometers). The height difference in the entry and exit peak lonospheric locations is indeed real. Due to insufficient information about the topside, it is also not possible to deduce a unique plasma scale height from these data. It is, however, apparent that the plasma temperature in the 63,000 to $68,000 \mathrm{~km}$ range is at least $500 \mathrm{~K}$, and perhaps as high as $1000 \mathrm{~K}$.

The Voyager 1 and 2 ionospheric measurements are shown in Figure 6. The radio occultation experiment of Voyager 1 during ingress covered a latitude range from $73^{\circ} \mathrm{S}$ to $79.5^{\circ} \mathrm{S}$ over a $14^{\circ}$ range of longitudes $/ 30 \%$ The immersion lonospheric measurements were carried out very near the beginning of this exercise; the latitude of the ionospheric region probed was $73^{\circ} \mathrm{S}$. A local peak at $2.4 \times 10^{4} \mathrm{~cm}^{-3}$ in the electron concentration was measured around $2500 \mathrm{~km}$; above and below the peak, the electron profile appears to be reduced in magnitude from that inferred from the Pioneer Saturn data. In either situation, it is difficult to determine the "true" plasma temperature from the scale height since the identity of the topside ion is not known with certainty. One can make only a qualitative comparison between the Pioneer Saturn and the voyager data because of the different observing frequencies and techniques, and the problems associated with fluctuations in the interplanetary solar wind electrons and the oscillator drift in the former. Furthermore, the voyager 1 data at $73^{\circ} \mathrm{S}$ are particularIy unsuitable for comparison as they represent polar conditions, while the Pioneer data are for the equatorial region. The Voyager data analysis in the region below $2000 \mathrm{~km} s$ hows considerable complex structure /31/ due, perhaps, to the presence of $\mathrm{H}_{3}^{+}$short-lived hydrocarbon Ions and long-lived metallic lons as proposed for Jupiter $132,4 /$. The metallic ions could be extraplanetary in origin such as from meteorites or from the Saturnian satellites. 


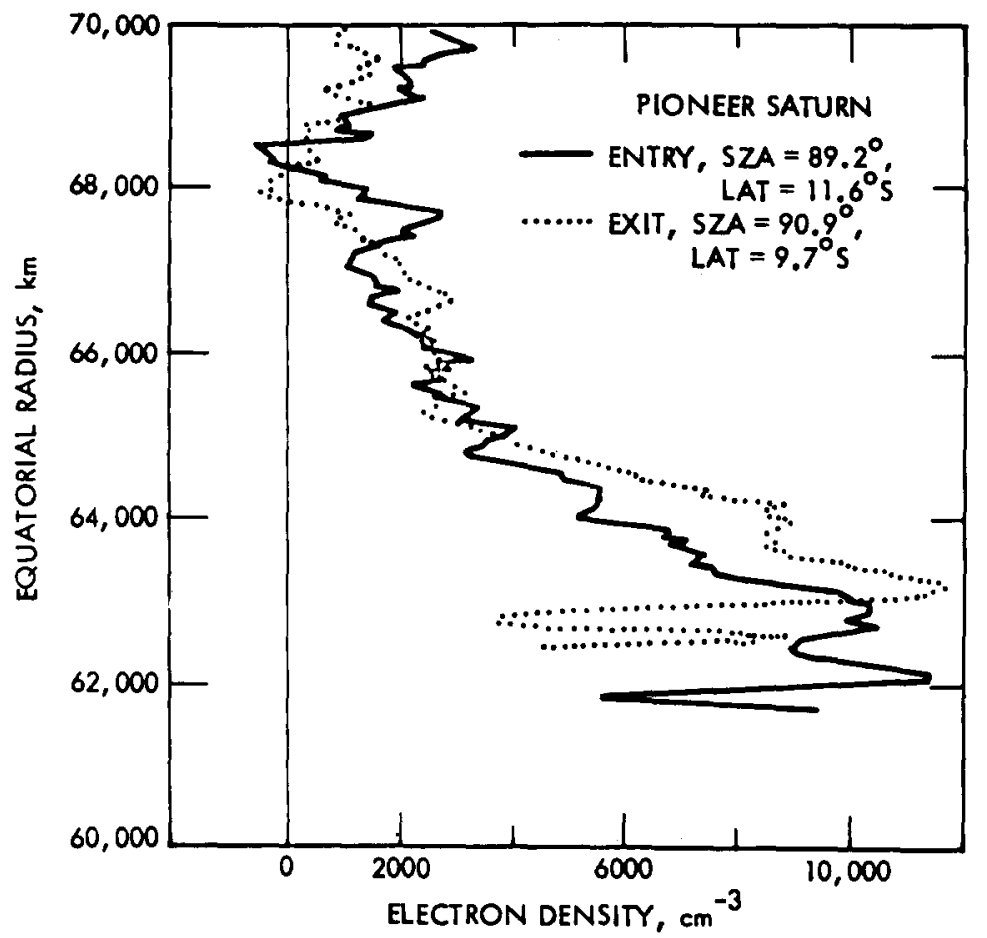

Fig. 5. Pioneer radio occultation profiles of Saturn (from $/ 29 /$ ).

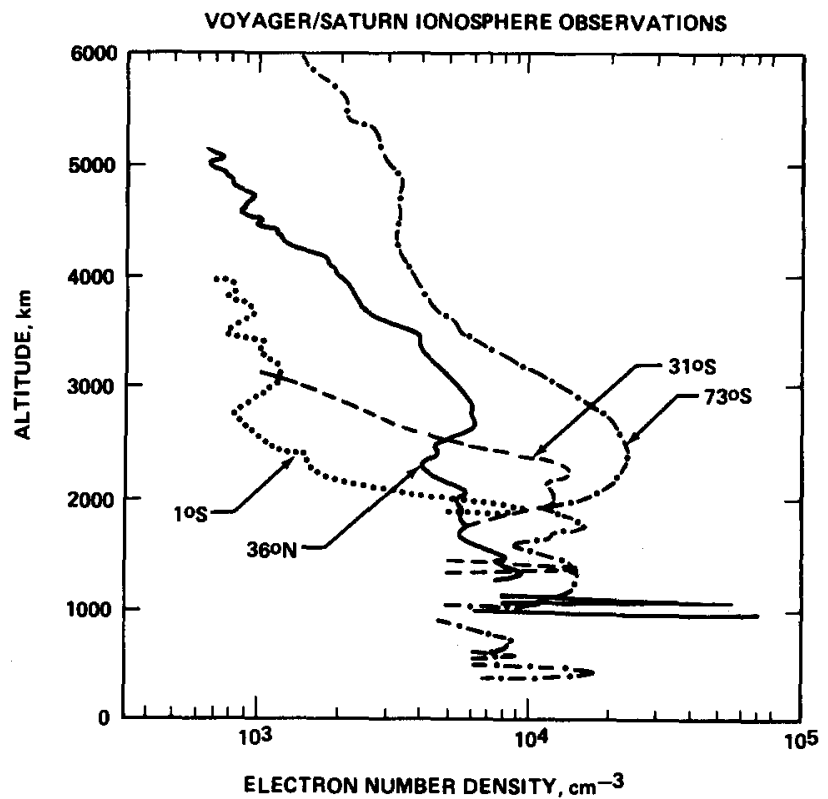

Fig. 6. Voyager radio occultation profiles of Saturn (from $/ 31 /$ ).

The voyager 2 ionospheric measurements are for mid-latitude conditions, with immersion at $36.5^{\circ} \mathrm{N}$ and emersion at $31^{\circ} \mathrm{S}$ (egress) $/ 33 \%$. Both measurements were made near the terminator, and both show "peak" electron concentrations somewhat lower than those measured on Voyager 1 in the polar region. The apparent peaks in the two Voyager 2 measurements are separated by nearly $700 \mathrm{~km}$. The topside scale height in the $2800-4000 \mathrm{~km}$ region of the ingress data is $1000 \mathrm{~km}$, approximately twice the topside scale height for voyager $1 / 34 /$. The Voyager 2 egress ionospheric profile has approximately the same topside scale height $(\sim 1100 \mathrm{~km})$ as the ingress one; the scale helght just above the peak $(2150 \mathrm{~km})$ in the egress, however, is 260 $\mathrm{km}$. The ionospheric data below $\sim 2000 \mathrm{~km}$ indicate that the Saturn lower lonosphere exhibits the type of multilayered structure seen on Jupiter. 


\section{Uranus Ionospheric Measurements}

The Voyager/Uranus Radio Science Team observed clear signatures of well separated lonospheric layers at altitudes of approximately 2000 to $3500 \mathrm{~km}$ above the 100 mbar pressure level. There is a possibility of an extended ionospheric layer that may reach altitudes of $10,000 \mathrm{~km}$ or more, with a peak density of several thousand electrons per cublc centimeter 135/. However, interpretation of the data pertaining to the topmost layer is somewhat uncertain due to large vartations in the background plasma associated with the solar wind. Therefore, no ionospheric profile is avallable at this time.

\section{Outer Planet Measurements}

Several striking discrepanctes exist upon comparing the outer planet ionospheric observations with pre-Voyager theoretical models: (1) The altitude of the primary (?) ionospheric peak is much higher than suggested by theoretical models. (2) The peak lonospheric density is lower than predictions, especially at Saturn. (3) There is extreme variance in the ionospheric profiles; the topside scale height at Saturn is extremely variable and at Jupiter and Saturn there are strong apparent dawn/dusk asymetries and auroral effects present. The Jupiter and Saturn profiles may indicate the presence of strong vertical drifts in the equatorial ionosphere. (4) Jupiter, Saturn, and Uranus observations indicate the presence of Ionospheric layering below the main peak.

$$
\text { THEORY, SPECULATION, AND OBSERVATION }
$$

\section{Jovian Low-Latitude Ionosphere}

Measurements of the neutral atmosphere structure at Jupiter using the Voyager UVS /6/ constrained the earlier models of the lonosphere. Photoionization by solar EUV radiation $\frac{1}{5}$ ncident upon this atmosphere leads to an ionospheric profile with a peak density of $6 \times 10^{5}$ $\mathrm{cm}^{-3}$ at an altitude of $750 \mathrm{~km}$ above the 1 bar pressure level at a planetocentric distance of $70,400 \mathrm{~km}$, well below the main ionospheric peak observed by voyager 1 radio occultation measurements at 1750 to $2250 \mathrm{~km}$ (see Figure 7). The study shown in Figure 7 and conducted by Chen $/ 36 /$ also showed that the effects of $\mathrm{H}_{2}$ (vib) charge exchange with $\mathrm{H}^{+}$were not sufficient to explain the discrepancy between the entry (afternoon) and exit (morning) Voyager 1 low-latitude Ionospheric observations as had been suggested by Atreya et al. $/ 11 /$. Chen /36/ used a vibrational temperature of $1600 \mathrm{~K}$ which did not vary with altitude or time. More comprehensive calculations by Cravens /14/ indicate higher vibrational temperatures and a greater change in the ionosphere, but indicate no diurnal variation of the ionosphere due to enhanced $\mathrm{H}_{2}$ vibrational temperatures.

\section{JUPITER IONOSPHERE}

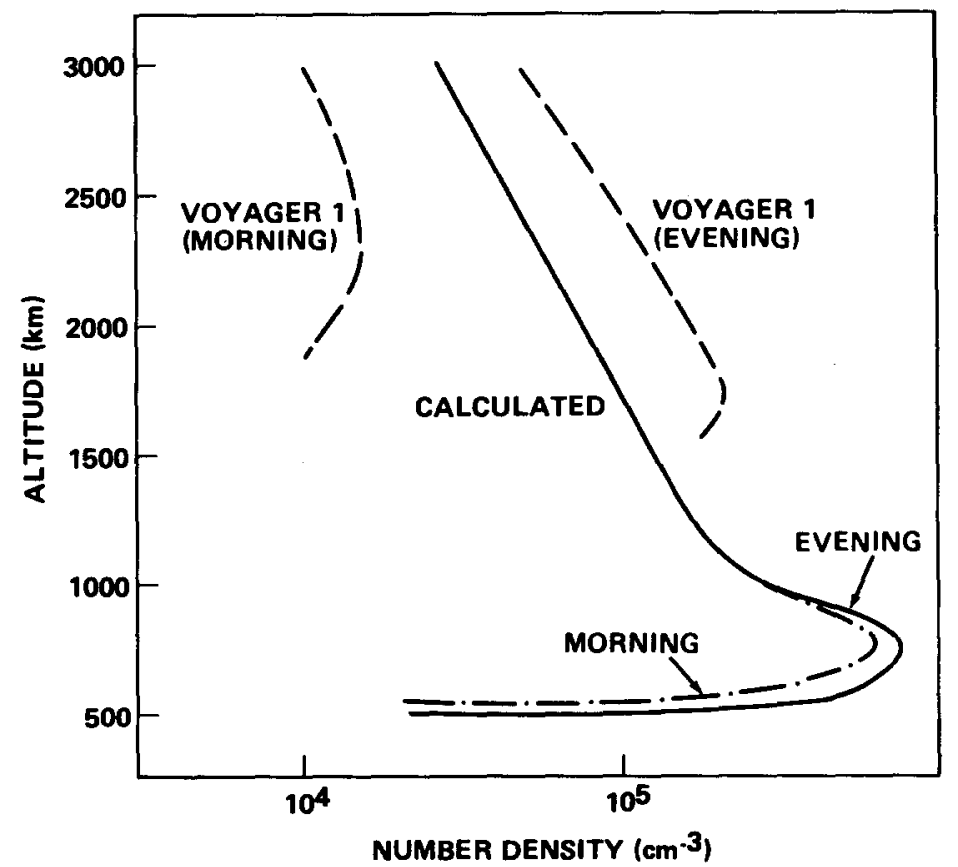

Flg. 7. Voyager 1 radio occultation measurements of the Jupiter lonosphere with time-dependent model calculations of the Jovian ionosphere (from $/ 36 /$ ). 
Independently Mahajan /37/ suggested that the difference between the Voyager 1 entry and exit profiles could be explained by a Jovian equatorial anomaly. Tan $/ 38$ / in a follow-up study of the Jovian equatorial anomaly indicated that if the available Jovian ionospheric measurements are ordered by dip latitude, there is some weak evidence that such an anomaly does exist (see Flgure 8). However, using a two-dimensional ionospheric model, he further demonstrated that the required low-latitude vertical drift speed would be several kilometers per second.

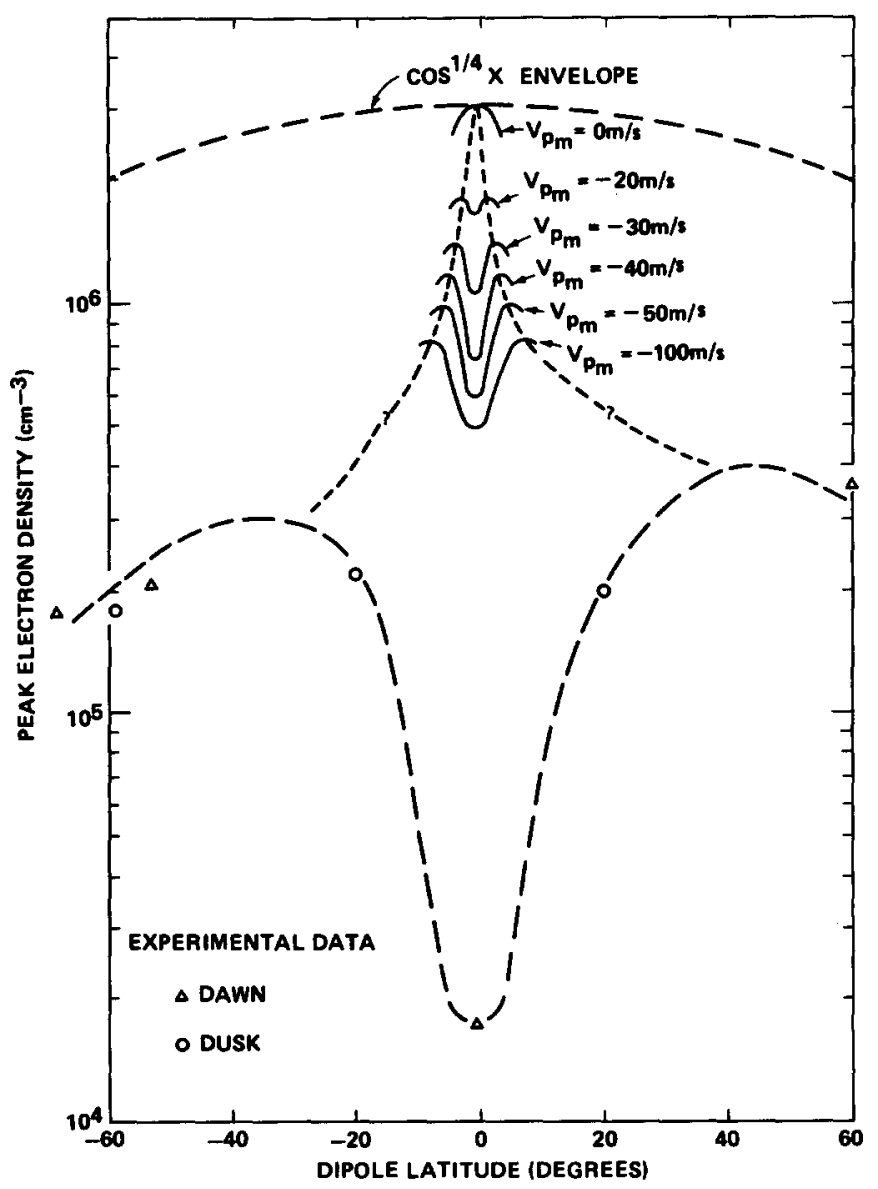

Fig. 8. $\mathrm{N}_{\mathrm{m}} \mathrm{F}_{2}$ for the Jovian ionosphere plotted as a function of dipole latitude with two-dimensional equatorial fountain model calculations superposed (from $/ 38 /$ ).

The ionosphere of Jupiter may also be influenced by the influx of water from satellites or meteorites. An influx of water from the rings of Saturn leads to a substantial diurnal variation of the Saturn ionosphere $118 /$. Water may also be present in the upper atmosphere of Jupiter $7^{\text {as }}$ inferfed from the observation of $\omega$ in the atmosphere $/ 39,40 /$. An influx of $\mathrm{H}, \mathrm{O}$ of $-10^{7} \mathrm{~cm}^{-2} \mathrm{~s}^{-f}$ is suggested by the observations, sufficient to significantly affect the ionosphere. A pronounced diurnal variation is also expected due to the decreased chemical lifetime of ions near the peak $\left(\sim 500 \mathrm{~s}\right.$ versus $>10^{5}$ for standard lonosphere models which exclude $\mathrm{H}_{2} \mathrm{O}$ ). Further modeling is needed to fully address this possibility.

Mcconnell et al. $/ 12 /$ used a combination of vertical drifts and enhanced $\mathrm{H}^{+}$loss due to charge exchange with $\mathrm{H}_{2}(\mathrm{~V}>4)$ to fit the observed Voyager ionospheric observations (see Figure 9). However, two major shortcomings of this study were: (1) the cholce of an arbitrary vibrational distribution for $\mathrm{H}_{2}$, and (2) ignoring the effects of particle ionization on the low- and high-latitude ionosphere.

As has been discussed earlier, particle lonization is important at low latitudes in the Jovian lonosphere. Figure 10 shows a mid-latitude theoretical profile obtained in this study using the new $\mathrm{H}_{3}{ }^{+}$and $\mathrm{H}_{2}$ vibrational chemistry as well as particle ionization processes (see the Ion Chemistry Overview and Sources of Ionization sections for details).

Voyager lonospheric measurements are shown for comparison. Three model profiles are shown: (1) the plus signs indicate a model profile where the only source of ionization is solar EUv radiation, (2) the dots indicate a profile where low-altitude "electroglow" ionization has been introduced with a total energy flux of $0.32 \mathrm{erg} \mathrm{cm}^{-2} \mathrm{~s}^{-1}$, and (3) the profile with $\mathrm{X}$ 's 
Indicates a model run where soft electron precipitation (100 ev) has been introduced into the top of the atmosphere with an energy flux of $0.32 \mathrm{erg} \mathrm{cm}^{-2} \mathrm{~s}^{-1}$. Elevated electron and Ion temperatures consistent with the particle ionization heating lead to the large topside plasma scale heights in the model. It is clear that particle lonization is needed to maintain the topside lonosphere density, yet there is no clear indication whether the electrons are internal ("electroglow") or external ("precipitating") to the ionosphere. It is also noted that the main lonospheric peak predicted by the model falls well below where the Voyager UVS measurements suggest the peak occurs, although the much needed low-altitude data have never been reduced.

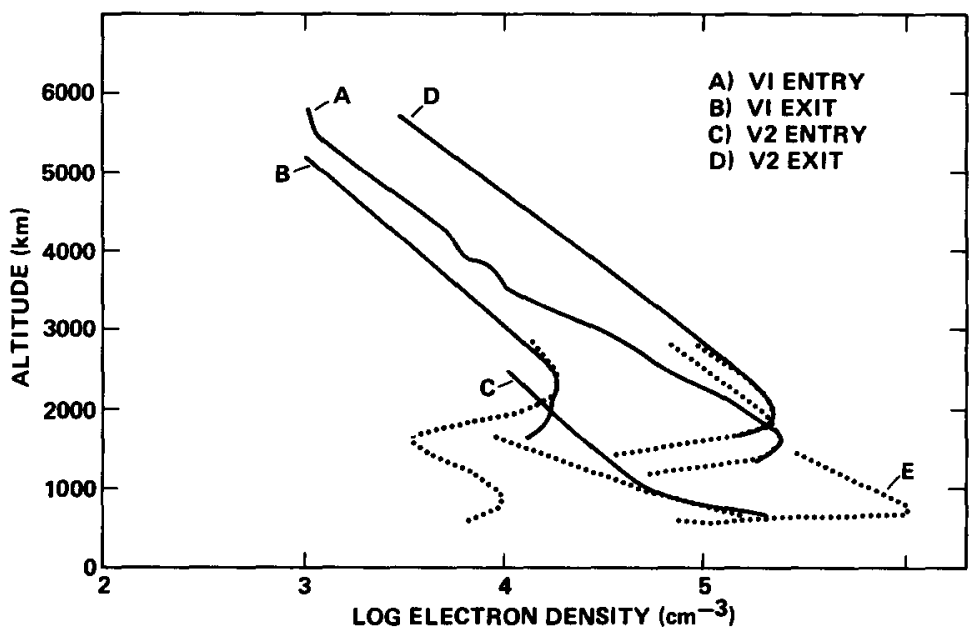

Fig. 9. Model fits to the Voyager ionospheric radio occultation data including vertical drifts and enhanced loss of $\mathrm{H}^{+}$via reaction with $\mathrm{H}_{2}(\mathrm{~V}>4)($ from $/ 12 /)$.

\section{JUPITER IONOSPHERE}

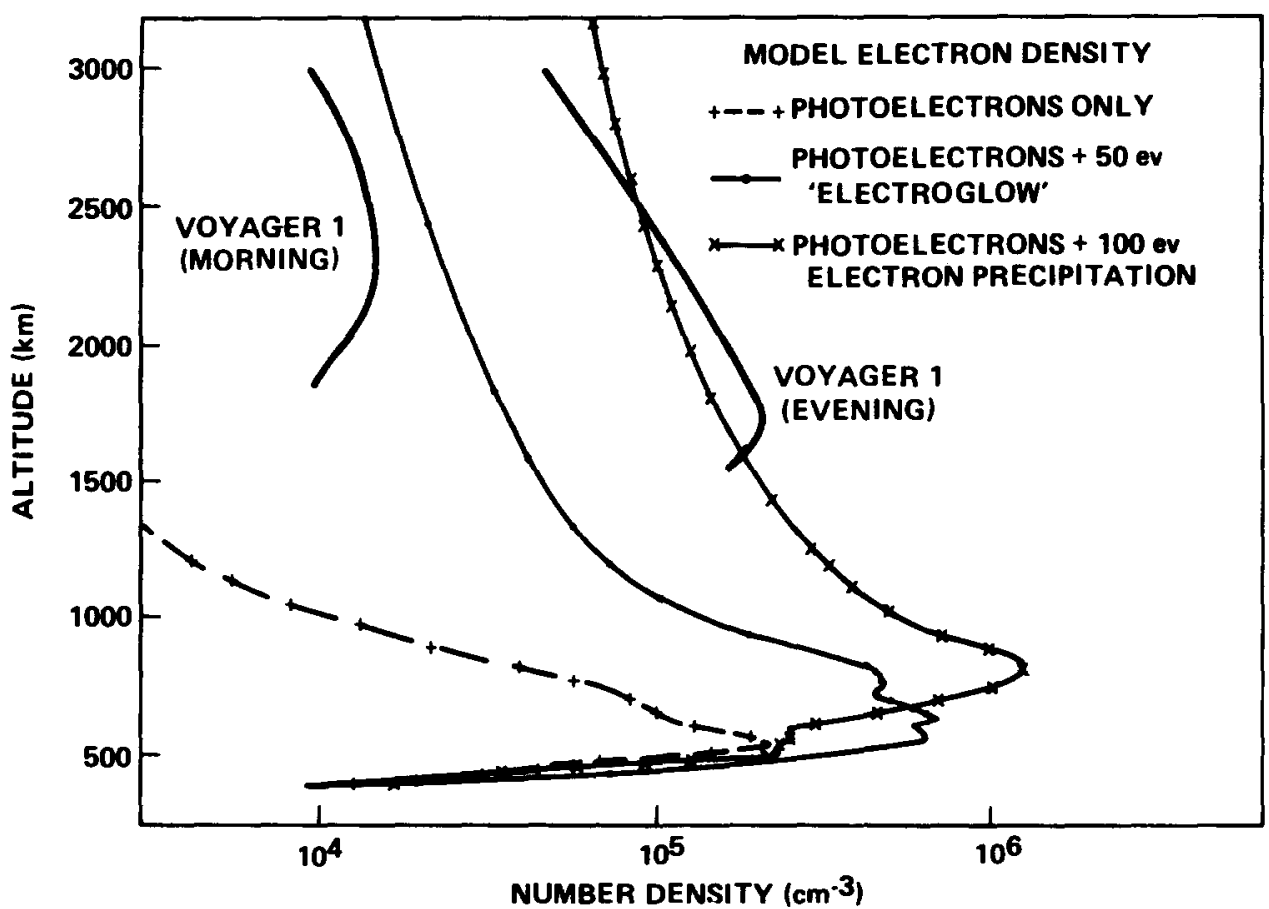

Fig. 10. Comparison of modeled and measured Jupiter mid-latitude electron density profiles. There are three model profiles. The profile with "+" considers only solar EUV ionization. The profile with dots includes as well "distributed" electroglow
particle ionization with a height integrated energy content of $0.32 \mathrm{erg} \mathrm{cm}^{-2} \mathrm{~s}^{-1}$. The " $\mathrm{X}$ " profile considers solar EUV plus $100 \mathrm{eV}$ electron precipitation with an energy influx of $0.32 \mathrm{erg} \mathrm{cm}^{-2} \mathrm{~s}^{-1}$ as suggested by Shemansky $/ 20 \%$ 


\section{Low-Altitude Ionospheric Layers}

Radio occultation measurements at Jupiter $/ 26 /$, Saturn $/ 31 /$, and Uranus $/ 35 /$ have revealed sharp layers of enhanced electron density in the lower ionosphere. Atreya et al. /32/ have suggested that such layers may be composed of long-lived metallic ions of meteoric or satellite origin. Strobel /15/ has estimated the Influx of heavy ions from the Galilean satellites into the Jovian atmosphere and used this influx and adiabatic ion acceleration to estimate the electron density of these layers. He found that moderate influxes could produce ionospheric layers with characteristics similar to the Pioneer Jupiter data. This preVoyager work was followed up in a more quantitative fashion by Chen /41/ who calculated the required $\mathrm{s}^{+}$influx and vertical wind shear in the upper atmosphere required to produce the Jovian $\mathrm{I}_{6}$ layer of the ionosphere (see Figure 11).

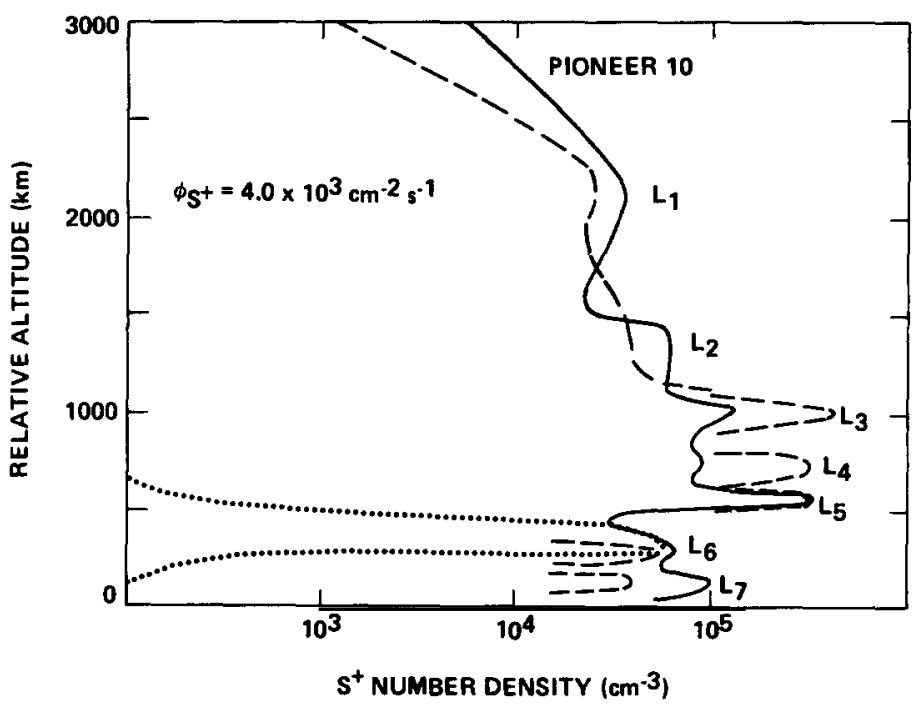

Fig. 11. Model calculation of the $S^{+}$flux required to reproduce the $I_{6}$ layer feature in the Jovian ionosphere (from $/ 41 /$ ).

Due to the multi-path propagation effects, the actual structure of these layers is extremely hard to determine using radio occultation measurements. Yet their importance cannot be overestimated since these layers lie in the appropriate ion-neutral collision frequency regime to be the dominant contributors to the integrated ionospheric conductivity. Therefore, they are extremely important in determining the degree of rotational coupling between the ionosphere and the magnetosphere.

\section{Jovian Auroral Ionosphere}

Over $10^{13}$ watts of power are dissipated into the Jovian atmosphere by auroxal processes $113 \%$. This huge amount of energy is extremely important in determining the high-latitude structure of the ionosphere and upper atmosphere through production of ionization, atomic hydrogen, and heat. Model calculations suggest $/ 13,14 /$ that auroral particle lonization processes lead to peak electron densities of $>10^{7} \mathrm{~cm}^{-3}$ using standard ionospheric models. However, the only available Voyager lonospheric profile in or near the auroral zone suggests a depleted topside ionosphere that is steeply increasing when it cuts off at an altitude $1000 \mathrm{~km}$ above the cloud tops (see the $\mathrm{V} 2$ entry profile in Figure 4). This suggests that other processes affect the auroral ionosphere. Waite et al. $/ 13 /$ suggested that $\mathrm{H}^{+}$charge exchange with $\mathrm{H}_{2}(\mathrm{~V}>4)$ could be important in the aurora as well as at low- and midlatitudes, since large quantities of vibrational excitation result from particle precipitation processes.

Cravens /14/ has made quantitative calculations of the $\mathrm{H}_{2}$ vibrational distribution in the upper atmosphere of Jupiter. He finds a very non-Boltzmann distribution with elevated vibrational temperatures in both the mid- and high-latitude atmosphere. He calculates that $\mathrm{H}^{+}$ charge exchange with $\mathrm{H}_{2}(\mathrm{~V}>4)$ can lead to a factor of 2 decrease in the mid-latitude lonosphere. At high latitudes in the auroral zone, he finds that although there is a copious production of $\mathrm{H}_{2}$ vibrational quanta, there is a corresponding increase in atomic hydrogen which moderates the vibrational bulldup through V-T collisions with higher $\mathrm{H}_{2}$ vibrational levels. However, if the aurora has just cut on and atomic hydrogen buildup has not occurred extensively and/or thermospheric winds have transported the atomic hydrogen out of the auroral region, significant effects on the lonosphere occur in the auroral region. Assuming nominal globally averaged values of $\mathrm{H}$ and aurorally enhanced $\mathrm{H}_{2}$ vibrational populations, Cravens /14/ obtains the lonospheric profiles $\mathrm{H}_{2}(\mathrm{~V})$ shown in Figure 12 that indicate over an 
order-of-magnitude reduction in the electron density profile due to charge exchange of $\mathrm{H}^{+}$ with $\mathrm{H}_{2}(\mathrm{~V}>4)$.

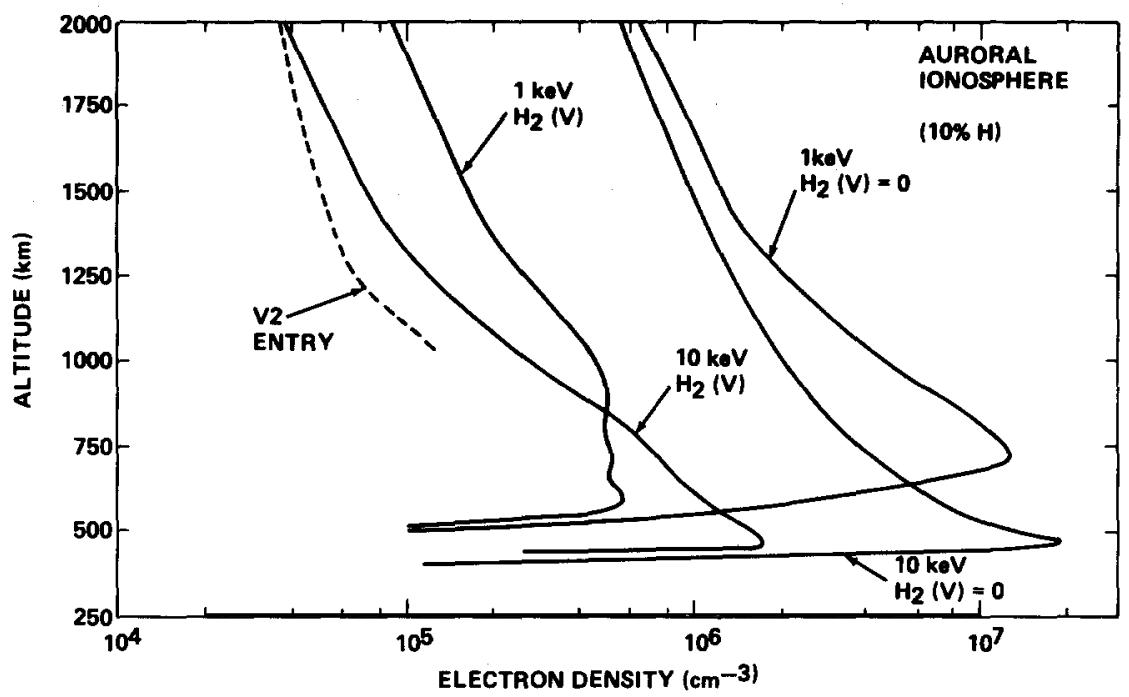

Fig. 12. Plot of the electron density as a function of altitude in the Jovian auroral zone for ionospheric calculations that have no vibrational $\mathrm{H}_{2}$ charge exchange with $\mathrm{H}^{+}$ $\left[\mathrm{H}_{2}(\mathrm{~V})=0\right]$ and for model calculations that contaln the $\mathrm{H}^{+}+\mathrm{H}_{2}(\mathrm{~V}>4)$ reaction labeled $\mathrm{H}_{2}(\mathrm{~V})$. The Voyager 2 high-latitude radio occultation profile $1 \mathrm{~s}$ also shown for comparison (from $/ 16 /$ ).

\section{Saturn's Ionospheric Rain}

Many features of the Saturnian Ionosphere were similar to the lonosphere at Jupiter: (1) the large vertical extent of the ionosphere, (2) high variability, and (3) the appearance of low-altitude ionospheric layers. Although, as in the case of Jupiter, these are important questions to consider, by far the most striking problem in the Saturnian ionospheric observations was the order-of-magnitude discrepancy between the observed topside ionospheric densities and those predicted by pre-encounter models /17/ illustrated in Figure 13 . Also the apparent altitude of the ionospheric peak altitude was higher than predicted by the models. Suggested explanations included ionospheric drifts and $\mathrm{ring}$ shadowing $/ 29 /, \mathrm{H}_{2}(\mathrm{~V}>$ 4) charge exchange $142 /$, and oH from the rings $/ 43,44 /$. However, the uniformity of all the dusk and dawn, low- and high-latitude radio occultation measurements made it difficult to ascribe to any one loss mechanism.

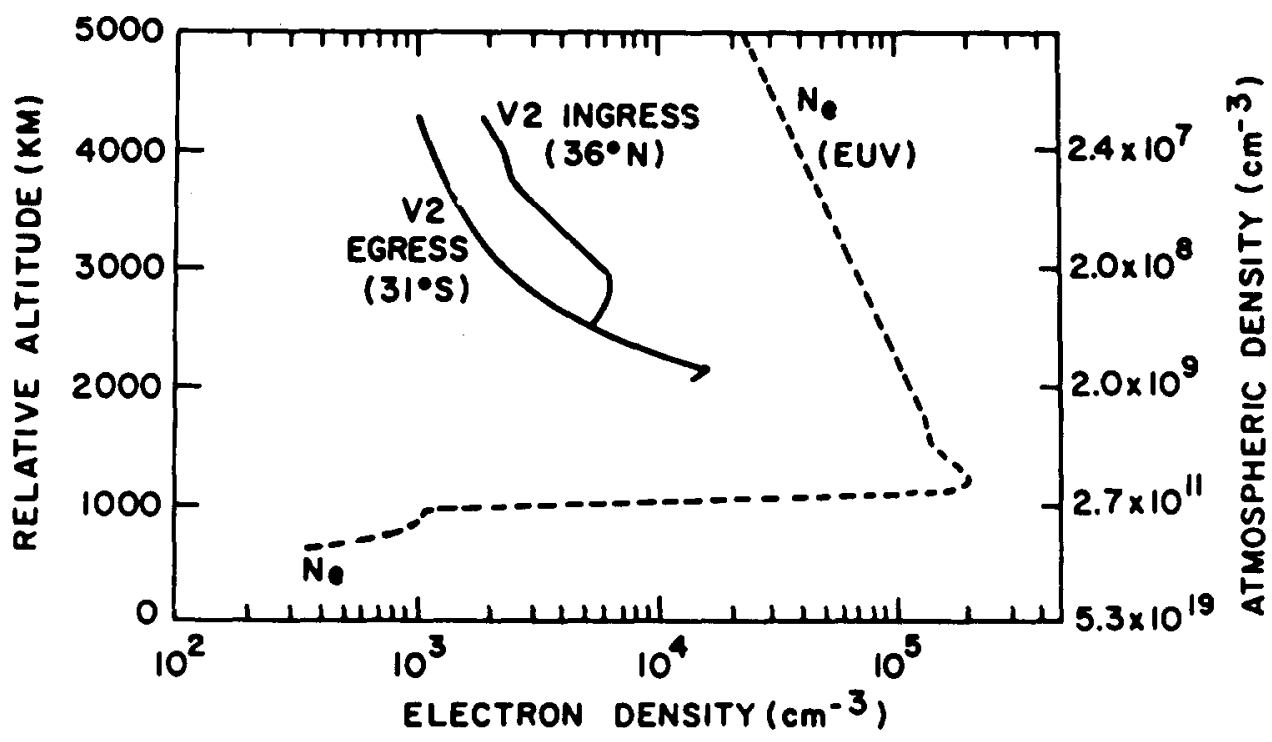

Fig. 13. Comparison of pre-Voyager model calculations of the Saturnian ionosphere with measured mid-latitude profiles of the ionosphere (from $/ 34 /$ ). 
However, luck was with us at Saturn. The Saturn lonosphere had its own internal lonosonde in the form of the low-frequency cutoff of the Saturn electrostatic discharges (SED) which originate from lightning deep within Saturn's equatorial atmosphere $145 /$. Kaiser et al. $/ 46 /$ used these SED radio measurements to overcome the dawn-dusk geometry restrictions of the radio occultation data and produced a diurnal profile of the Saturn lonosphere shown in Figure 14. What they found was very unexpected, an lonosphere whose peak noontime density was $2 \times 10^{5} \mathrm{~cm}^{-3}$, much as predicted by pre-encounter models, but whose nighttime density fell to less than $10^{3} \mathrm{~cm}^{-3}$ with a value of $10^{4} \mathrm{~cm}^{-3}$ at the day and night terminators in agreement with the radio occultation measurements. Moreover, they observed a latitudinal signature that mapped magnetically to important structures in the rings $/ 18 \%$. The expected long lifetime of $\mathrm{H}^{+}$in the topside lonosphere of $>10^{6} \mathrm{~s}$ predicted by earlier models was definitely incorrect; at Saturn, some other dominant chemical loss process must be occurring.

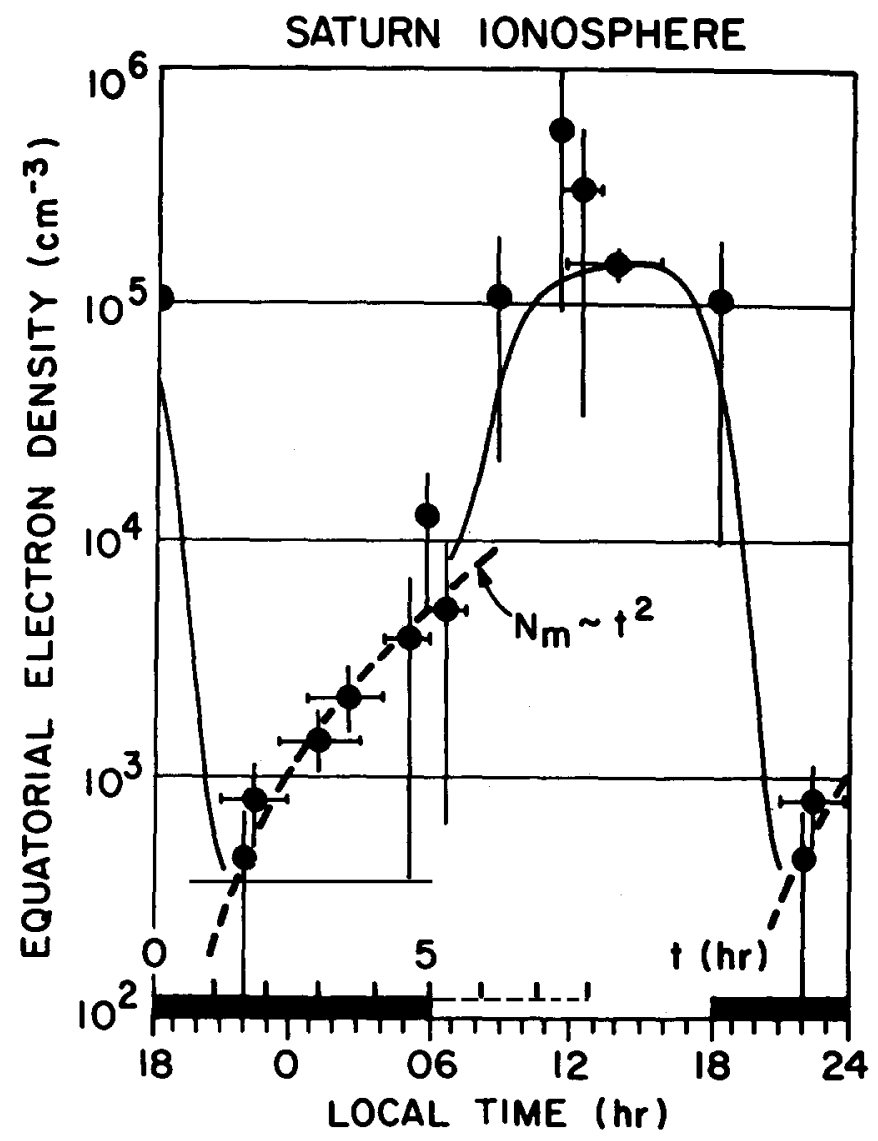

Fig. 14. Profile of the diurnal variation of $\mathrm{N}_{\mathrm{m}} \mathrm{F}_{2}$ in the Saturnian ionosphere (from /18/).

The strong diurnal variation and the latitudinal variations of the lonosphere magnetically associated with features in the ring plane led Connerney and Waite $/ 18$ / to follow the earlier suggestion of Shimizu /43/ and Chen /44/ that water from the rings was flowing down into the Saturn upper atmosphere and causing major modifications to the Saturn ionospheric structure. An influx of $1 \times 10^{7} \mathrm{~cm}^{-2} \mathrm{~s}^{-1}$ of water molecules was sufficient to explain the low lonospheric densities observed at Saturn. The $\mathrm{H}_{2} \mathrm{O}$ would then catalytically transform $\mathrm{H}^{+}$ into the molecular ions $\mathrm{H}_{3} \mathrm{O}^{+}$which recombines rapidly reforming $\mathrm{H}_{2} \mathrm{O}$ as shown schematically in Figure 15. The major reaction channel is charge exchange of $\mathrm{H}^{+2}$ with $\mathrm{H}_{2} \mathrm{O}$ to form $\mathrm{H}_{2} \mathrm{O}^{+}$ which rapidiy reacts with $\mathrm{H}_{2}$ to form $\mathrm{H}_{3} \mathrm{O}^{+}$. $\mathrm{H}_{3} \mathrm{O}^{+}$then recombines with electrons reforming $\mathrm{H}_{2} \mathrm{O}$. The result of the water chemistry combined with particle ionization sources due to "electroglow" processes (see the Sources of Ionization section for details on the "electroglow" particle iontzation source) is shown in the ionospheric profile of Flgure 16. This steady state calculation shows that the rapid $108 s$ of $\mathrm{H}^{+}$due to charge exchange of water decreases $\mathrm{H}^{+}$significantly and forms $\mathrm{H}_{3} \mathrm{O}^{+}$. The recently measured slower recombination of $\mathrm{H}_{3}{ }^{+}$coupled with the rapid loss of $\mathrm{H}^{+}$leads to a layered lonosphere dominated by $\mathrm{H}^{+}$in the topside, $\mathrm{H}_{3} \mathrm{O}^{+}$near $1500 \mathrm{~km}, \mathrm{H}_{3}{ }^{+}$with a double peaked structure at 1000 and $3000 \mathrm{~km}$, and hydrocarbon lons below $1000 \mathrm{~km}$. "Representative" Voyager profiles are shown for comparison. The agreement is not bad consldering the model calculations are steady state. The model also reproduces the low-altitude layer seen in the Voyager/Saturn data of Figure 6. This layer is formed in the model by $\mathrm{H}_{3}^{+}$and hydrocarbon ions. Similar results have been ob- 
tained by Majeed and McConnell /47/. However, from both measurements and theory we know that the steady state conditions of Flgure 16 will never prevail and that there will be a continuous cycle favoring $\mathrm{H}_{3} \mathrm{O}^{+}$dominance during the day and conversion to $\mathrm{H}_{3}{ }^{+}$at $\mathrm{night}$. Time-dependent calculations currently being performed are necessary to elucidate the behavior of the Saturn ionosphere. Further careful calculations of the chemistry of $\mathrm{H}_{2} \mathrm{O}$ in the Saturn upper atmosphere are also necessary before conclusive calculations can be made.

\section{SATURN IONOSPHERE} (WATER MODEL)

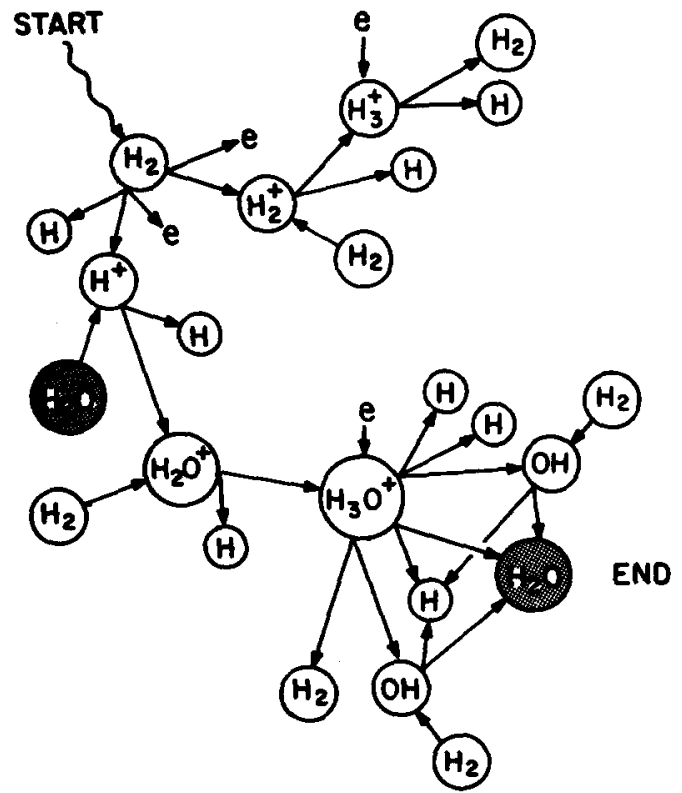

Fig. 15. Schematic of the $\mathrm{H}^{+}$and $\mathrm{H}_{2} \mathrm{O}$ chemistry thought to be of importance in the ionosphere of Saturn.

\section{SATURN IONOSPHERE}

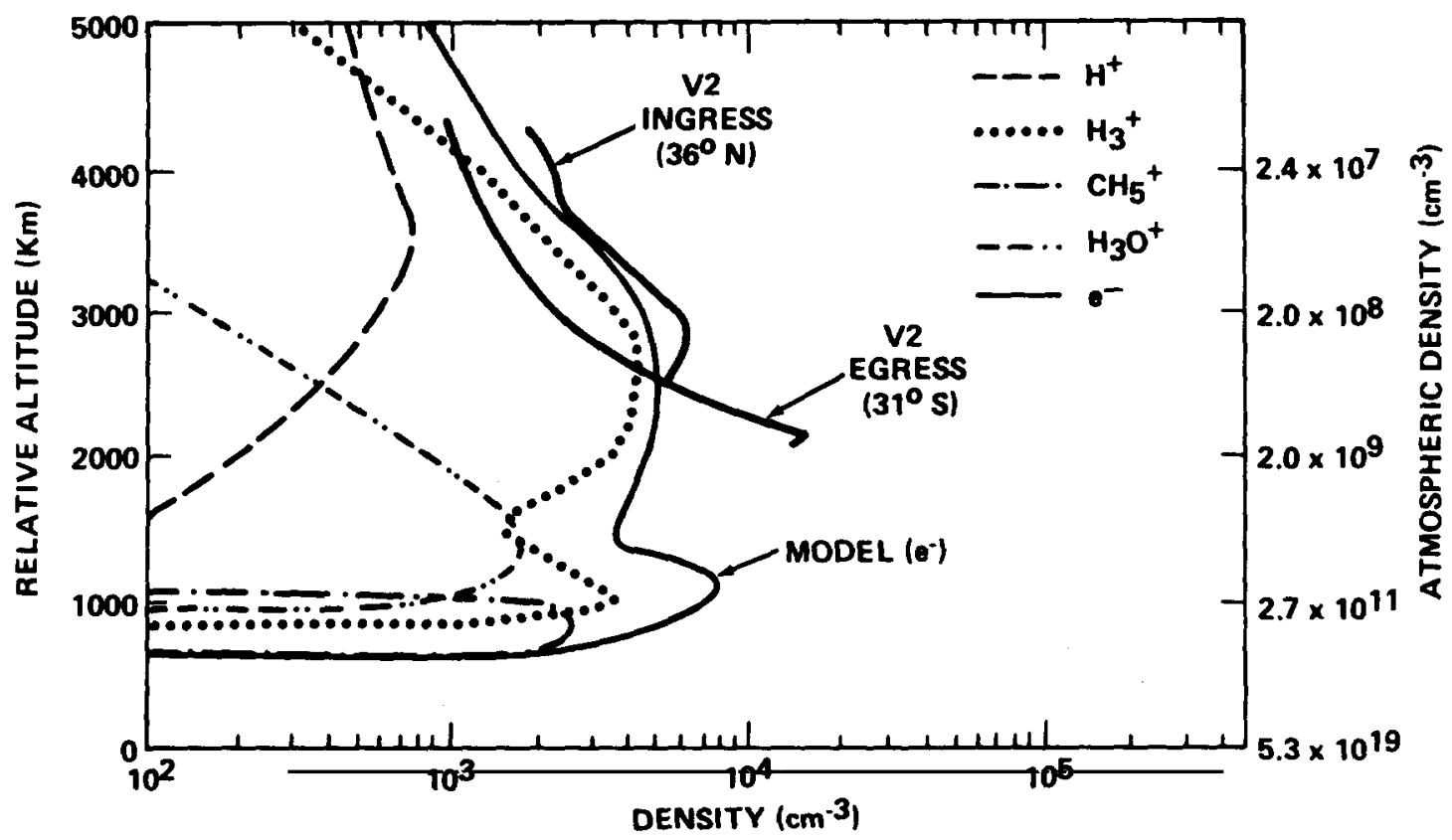

Fig. 16. Model ionospheric profile of Saturn 1llustrating the effects of $\mathrm{H}_{2} \mathrm{O}$ influx from the rings on the lonospherle composition and structure and incluaing particle ionization sources due to "electroglow" processes. 


\section{Uranus Ionosphere Models}

The first model of the lonosphere of Uranus was that of McElroy $/ 2 \%$. It depicted the ionosphere as being similar to the lonospheres of Jupiter and Saturn, composed mainly of protons and reaching a density of slightly greater than $10^{5} \mathrm{~cm}^{-3}, 100 \mathrm{~km}$ above an atmospheric density level of $10^{16} \mathrm{~cm}^{-3}$. More recent models /48,49/ used updated chemistry and neutral atmospheric models and obtained similar results for a standard $\mathrm{H}_{2}$ atmosphere. However, Chandler and Waite $/ 19 /$ also modeled the effects of both particle precipitation and $\mathrm{H}_{2} \mathrm{O}$ and $\mathrm{CH}_{4}$ influx on the lonospheric structure.

Uranus, like both Jupiter and Saturn, shows pronounced dayside emissions at Lyman alpha and in the Lyman and Werner band systems that indicate a column integrated energy flux of 0.1 erg $\mathrm{cm}^{-2} \mathrm{~s}^{-1}$ from soft $(<15 \mathrm{eV})$ electrons. This phenomenon has been recentiy termed "electroglow." The effect of this energy influx on the Uranus ionospheric structure is illustrated in Figure 17. The solid line shows a standard model atmosphere with a neutral temperature and composition defined by the Voyager IRIS/RSS/UVS measurements, but with the only energy source being solar EUV radiation. The dashed line incorporates the effect of an "electroglow" soft electron component of $15-\mathrm{eV}$ electrons with a total energy flux of 0.1 erg $\mathrm{cm}^{-2} \mathrm{~s}^{-1}$ and whose altitude distribution follows the photoelectron production profile.

The Iimited Voyager/RSS Ionospheric information we presently have suggests an ionosphere with multilayered structure, greatly extended in altitude and with a peak density of a few thousand electrons per cubic centimeter. The extended ionosphere is a simple consequence of the hot exospheric temperature and relatively low gravitation acceleration at uranus. It is present in all the profiles of Figure 17 (although not shown in the dotted curve due to decreased densities of the order of $\left.10^{2} \mathrm{~cm}^{-3}\right)$. However, an ionospheric peak density of $<10^{4}$ $\mathrm{cm}^{-3}$ suggests that elther $\mathrm{CH}_{4}$ or $\mathrm{H}_{2} \mathrm{O}$ influx may play a significant role at Uranus as at Saturn. $\mathrm{CH}_{4}$ influx seems to be ruled out by the UVS measurements leaving open the possibility of $\mathrm{H}_{2} \mathrm{O}$ influx. The effect of an influx of $10^{8} \mathrm{~cm}^{-2} \mathrm{~s}^{-1} \mathrm{H}_{2} \mathrm{O}$ molecules on the Uranus ionosphere is shown by the dotted line in Flgure 17. The peak density is $9 \times 10^{3} \mathrm{~cm}^{-3}$ with a peak near $3700 \mathrm{~km}$.

\section{URANUS IONOSPHERE}

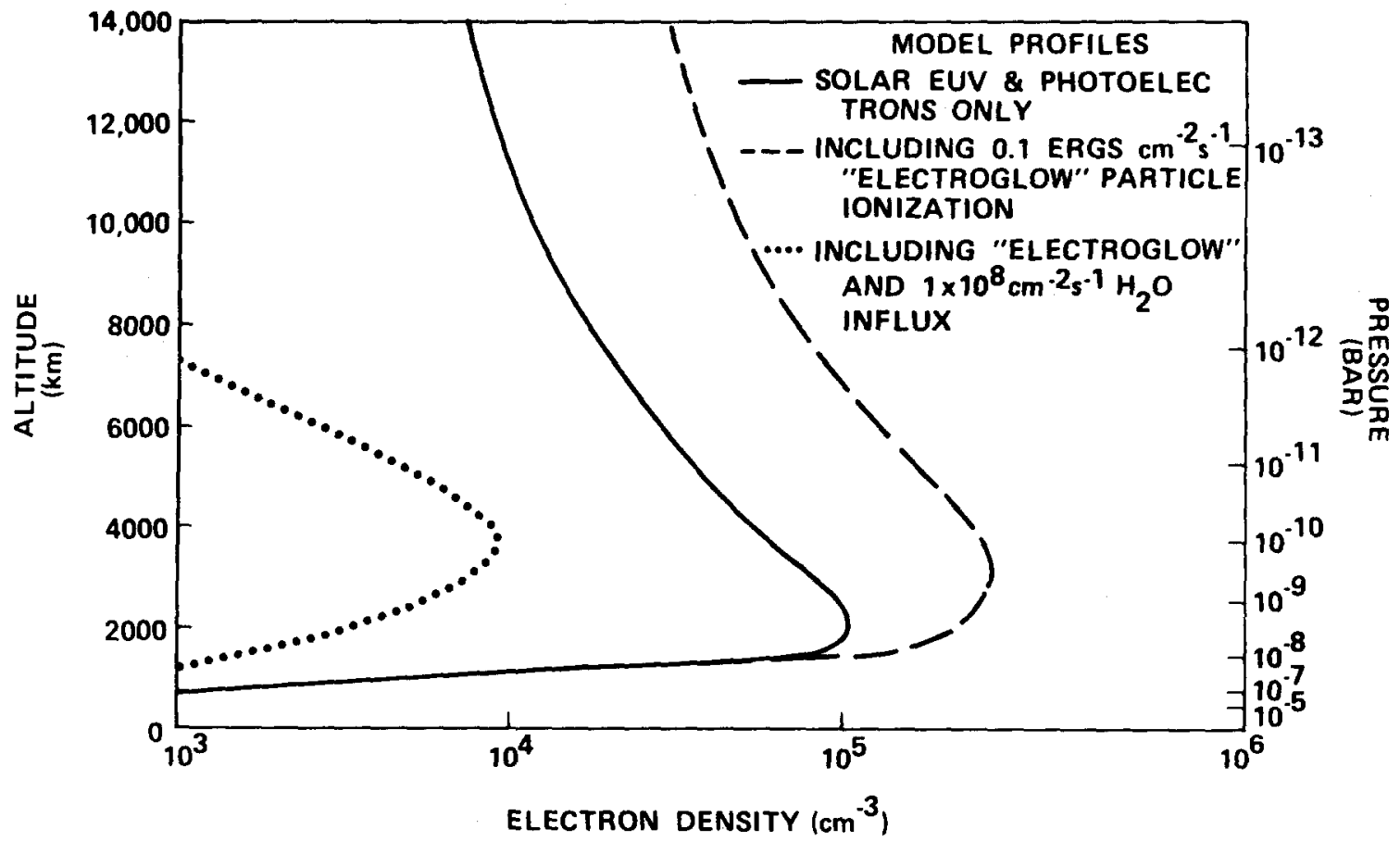

Fig. 17. Model Lonospheric profiles for Uranus using the Voyager inferred temperature profiles and showing the effects of particle lontzation and $\mathrm{H}_{2} \mathrm{O}$ influx on the ionosphere.

The observed multilayered structure of the fonosphere is probably the result of a combination of influences including $\mathrm{H}_{2} \mathrm{O}$ influx, $\mathrm{H}_{3}{ }^{+}$ionospheric structure (suggested by the above calculations), and distribution of meteoric or satelifte material in the lonosphere $/ 48 /$. The recurrence of the multilayered structure in all the outer planet ionospheres of Jupiter, Saturn, and Uranus certainly suggests that this phenomenon warrants further study. 


\section{CONCLUSIONS AND FUTURE DIRECTIONS}

In this review, we have concentrated on the interesting interplay of Pioneer Voyager ionospheric measurements with post-Voyager theory. A multitude of interesting phenomena are present in the outer planetary systems, some of which have terrestrial anologies, such as ionospheric layering, auroral influences, and equatorial anomalies, and some of which are new and unique, such as water from the Saturn rings and "electroglow." Much new information is needed for this relatively new field of study, not the least of which are in situ ionospheric measurements, such as might be possible on future missions such as Jupiter Polar orbiter. Yet before that time, there is still plenty we can do from our terrestrial perspective to enhance the study of major planet ionospheres. I would like to end with a partial list of outstanding problems that need to be addressed to make further progress.

OUTSTANDING PROBLEMS CONCERNING MAJOR PLANET IONOSPHERES

\section{Theoretical}

(1) Determine the mechanism for solar EUV control of soft electron precipitation, the "electroglow," over the whole dayside atmospheres of Jupiter, Saturn, Titan, and Uranus.

(2) Develop a time-dependent ionosphere model to correctly calculate the coupled transport and chemistry effects in the ionosphere through a planetary day.

(3) Understand the effects of thermospheric circulation on the auroral 1onospheres of Jup1ter and Saturn.

(4) Determine the role of $\mathrm{H}_{2} \mathrm{O}$ chemistry in the upper atmospheres of Jupiter, Saturn, and Uranus.

\section{Laboratory Measurements}

(1) Measure the $\mathrm{H}_{3}{ }^{+}$recombination rate as a function of vibrational level.

(2) Measure the $\mathrm{H}^{+}+\mathrm{H}_{2}(\mathrm{~V}>4)$ reaction rate.

(3) Measure airglow cross sections for energetic $\mathrm{o}^{+\mathrm{q}}, \mathrm{s}^{+\mathrm{q}}$, and $\mathrm{Na}+\mathrm{q}$ on $\mathrm{H}_{2}$ and $\mathrm{H}$.

(4) Measure branching rates for metastable Ion chemistry taking into account vibrational excitation of the reacting species.

\section{Spacecraft Measursements}

(1) Analyze low-altitude $(<2000 \mathrm{~km})$ Voyager Ionosphere data for Jupiter and Uranus.

(2) Make new measurements of the global variations of the ionospheres of Jupiter and Saturn. REFERENCES

1. D.M. Hunten, J. Atmos, Sci. 26, 826 (1969).

2. M.B. McElroy, Space Sc1. Rev. 14, 460 (1973).

3. W.T. Huntress, Jr., Advan. At. Mol. Phys. 10, 295 (1974).

4. S.K. Atreya and T.M. Donahue, Model Ionospheres of Juplter, in: Jupiter, ed. T. Gehrels, Univ, of Arizona Press, Tucson, AZ 1976, p. 304.

5. D.F. Strobel, Rev. Geophys. Space Phys. 17, 1913 (1979).

6. M.C. Festou, S.K. Atreya, T.M. Donahue, B.R. Sandel, D.E. Shemansky, and A.L. Broadfoot, J. Geophys. Res. 86, 5715 (1981).

7. M.C. Festou and S.K. Atreya, Geophys. Res. Lett. 9, 1147 (1982).

8. G.R. Smith, D.E. Shemansky, J.B. Holberg, A.I. Broadfoot, B.R. Sande1, and J.C. MCConnell, J. Geophys. Res. 88, 8667 (1983).

9. A.L. Broadfoot, F. Herbert, J.B. Holberg, D.M. Kunten, S. Kumar, B.R. Sande1, D.E. Shemangky, G.R. Smith, R.V. Yelle, D.F. Strobel, H.W. Moos, T.M. Donahue, S.K. Atreya, J.L. Bertaux, J.E. Blamont, J.C. MeConnell, A.J. Dessler, S. Tinick, and R. Springer, Ultraviolet spectrometer observations of Uranus, Science in press (1986).

10. M.T. Leu, M.A. Biond1, and R. Johnsen, Phys. Rev. 8, 413 (1973).

11. S.K. Atreya, T.M. Donahue, and J.H. Waitte, Jr., Nature 280, 795 (1979).

12. J.C. McConnell, J.B. Holberg, G.R. Smith, B.R. Sandel, D.E. Shemansky, and A.L. Broadfoot, Planet. Space Sci. 30, 151 (1982).

13. J.H. Waite, Jr., T.E. Cravens, J. Kozyra, A.F. Nagy, and S.K. Atreya, J. Geophys. Res. $88,6143(1983)$.

14. T.E. Cravens, Vibrationally excited molecular hydrogen in the upper atmosphere of Jupiter, J. Geophys. Res. submitted (1986).

15. D. Smith and N.G. Adams, Astrophys. J. (Letters) 284, L13 (1984).

16. H.H. Michels and R.H. Hobbs, Astrophys. J. (Letters) 286, L27 (1984). 
17. J.K. Waite, Jr., S.K. Atreya, and A.F. Nagy, Geophys. Res. Lett. 6, 723 (1979).

18. J.E.P. Connerney and J.H. Walte, Jr., Nature 312,136 (1984).

19. M.O. Chandler and J.H. Waite, Jr., Geophys. Res, Lett. 13, 6-9 (1986).

20. D.E. Shemansky, J. Geophys. Res. 90,2673 (1985).

21. R.V. Yelle, B.R. Sandel, D.E. Shemansky, and S. Kumar, The altitude variation of EUV emissions and evidence for proton precipitation at low latitudes in the Saturnian atmosphere, J. Geophys. Res. in press (1986).

22. V.R. Eshleman, Planet. Space Sci. 21, 1521 (1973).

23. G. Fjeldbo, Planet. Space Sci. 21, 1533 (1973).

24. D.M. Hunten and J. Veverka, Stellar and spacecraft occultations, in Jupiter, ed. T. Gehrels, Univ, of Arizona Press, Tucson, Az 1976, p. 247.

25. V.R. Eshleman, G.L. Tyler, J.D. Anderson, G. Ffeldbo, G.S. Levy, G.E. Wood, and T.A. Croft, Space Science Rev. 21, 207 (1977).

26. G. Fjeldbo, A. Kliore, B. Seldel, D. Sweetnam, and D. Cain, Astron. Astrophys. 39, 91 (1975).

27. V.R. Eshleman, G.L. Tyler, G.E. Wood, G.F. Lindal, J.D. Anderson, G.S. Levy, and T.A. Croft, Science 204, 976 (1979).

28. V.R. Eshleman, G.L. Tyler, G.E. Wood, G.F. Lindal, J.D. Anderson, G.S. Levy, and T.A. Croft, Science 206, 959 (1979).

29. A.J. Kliore, I.R. Patel, G.F. Linda1, D.N. Sweetnam, H.B. Hotz, J.H. Walte, Jr., and T.R. MeDonough, J. Geophys. Res. 85, 5857 (1980).

30. G.L. Tyler, V.R. Eshleman, J.D. Anderson, G.S. Levy, G.F. Lindal, G.E. Wood, and T.A. Croft, Science 212, 201 (1981).

31. G.F. Linda1, D.N. Sweetnam, and V.R. Eshleman, Astron. Journal 90, 1136 (1985).

32. S.K. Atreya, T.M. Donahue, and M.B. McElroy, Sclence 184, 154 (1974).

33. G.I. Tyler, V.R. Eshleman, J.D. Anderson, G.S. Levy, G.F. Lindal, G.E. Wood, and T.A. Croft, Science 215, 553 (1982).

34. S.K. Atreya, T.M. Donahue, A.F. Nagy, J.H. Watte, Jr., and J.C. McConnell, Theory, measurements, and models of the upper atmosphere and ionosphere of Saturn, in: Saturn, ed. T. Gehrels, Univ, of Arizona Press, Tucson, AZ 1984, p. 239.

35. G.L. Tyler, D.N. Sweetnam, J.D. Anderson, J.K. Campbell, V.R. Eshleman, D.P. Hingon, G.S. Levy, G.F. Lindal, E.A. Marouf, and R.A. Simpson, Radio science observations of the Uranian system with Voyager 2: Properties of the atmosphere rings, and satellite, Science in press (1986).

36. R.F. Chen, J. Geophys. Res. 87, 167 (1982).

37. K.K. Mahajan, Geophys. Res. Lett. 8, 66 (1981).

38. A. Tan, Jovian Ionosphere ModeI with Electrodynamic Drift, Final Project Report of NSF Grant No. ATM-8308276 (March 1985).

39. M.J. Prather, J.A. Logan, and M.B. McElroy, Astrophys. J. 223, 1072 (1978).

40. D.F. Strobel and Y.L. Yung, Icarus 37, 256 (1979).

41. R.H. Chen, J. Geophys. Res, 87, 7792 (1981).

42. S.K. Atreya and J.H. Waite, Jr., Nature 292, 682 (1981).

43. M. Shimizu, Strong interaction between the ring system and the lonosphere of Saturn, in: Proc. 13th Lunar Planet. Symp., 1980, p. 709.

44. R.H. Chen, Moon Planets 28, 37 (1983).

45. M.I. Kaiser, J.E.P. Connerney, and M.D. Desch, Nature 303, 50 (1983).

46. M.L. Kalser, M.D. Desch, and J.E.P. Connerney, J. Geophys. Res. 89, 2371 (1984).

47. T. Majeed and J.C. McConnell, EOS 67, 318 (1986).

48. S.K. Atreya and J.J. Ponthieu, Planet. Space Sci. 31, 939-944 (1983). 